\title{
$\beta$-Adrenergic Receptors: Astrocytic Localization in the Adult Visual Cortex and Their Relation to Catecholamine Axon Terminals as Revealed by Electron Microscopic Immunocytochemistry
}

\author{
Chiye Aoki \\ Center for Neural Science and Biology Department, New York University, New York, New York 10003
}

It has long been recognized that noradrenaline, the most abundant catecholamine within the visual cortex, plays important roles in modulating the sensitivity of cortical neurons to visual stimuli. However, whether or not these noradrenaline effects are confined to a discrete synaptic specialization or mediated by diffuse modulation of a group of synapses has remained an issue open for debate. The aim of this study was to examine the cellular basis for noradrenaline action within the visual cortex of adult rats and cats. To this end, I used electron microscopic immunocytochemistry to examine the relationship between (1) catecholamine axon terminals and $\beta$-adrenergic receptors ( $\beta$ AR), which, together, may define the effective sphere of noradrenaline modulation; and then (2) these putative sites for catecholamine modulation and axospinous asymmetric junctions where excitatory neurotransmission is likely to dominate. Antibodies against BAR were used at light and electron microscopic levels on the visual cortex of rat and cat. Rat visual cortex was also labeled simultaneously for $\beta A R$ and the catecholamine-synthesizing enzyme, tyrosine hydroxylase (TH), to determine the ultrastructural relationships between catecholamine terminals and $\beta A R$. Immunoperoxidase labeling revealed that $\beta A R 404$, a polyclonal antibody directed against the $\mathrm{C}$-terminal tail of hamster lung $\beta A R\left(\beta_{2}\right.$-type), recognized astrocytic processes predominantly. In contrast, $\beta$ AR248, a polyclonal antibody directed against the third cytoplasmic loop, recognized neuronal perikarya as observed in previous studies. Dual labeling for $\beta A R 404$ and TH revealed that catecholamine axon terminals that contained numerous vesicles formed direct contacts with astrocytic processes exhibiting BAR404 immunoreactivity. However, some catecholamine axon terminals that lacked dense clusters of vesicles were positioned away from BAR404-immunoreactive astrocytes. Frequently, $\beta$ AR-immunoreactive astrocytic processes surrounded asymmetric axospinous junctions while also contacting catecholamine axon terminals. These observations support the possibility that, through activation of astrocytic $\beta A R$, noradrenaline modulates astrocytic uptake mechanism

Received June 12, 1991; revised Oct. 7, 1991; accepted Oct. 7, 1991.

I am grateful to Dr. Catherine D. Strader at Merck Sharp and Dohme Research Laboratories for her generous gifts of antibodies against $\beta$ AR. I thank Adam Starr for his help in processing the tissue for electron microscopy and Dr. Scott Berger at Cornell University Medical College for performing the computerized search of amino acid sequence homology. I thank Dr. Strader and the reviewers for their comments on the manuscript. This work was funded by EY08055 from the National Institutes of Health.

Correspondence should be addressed to Chiye Aoki, Ph.D., Center for Neural Science, New York University, 6 Washington Place, New York, NY 10003.

Copyright (C) 1992 Society for Neuroscience $0270-6474 / 92 / 120781-12 \$ 05.00 / 0$ for excitatory amino acids, such as L-glutamate. Astrocytic $\beta A R$ might also define the effective sphere of catecholamine modulation through alterations in the morphology of distal astrocytic processes and the permeability of gap junctions formed between astrocytes.

In the visual cortex of rat, cat, and monkey, the supragranular laminae are densely innervated by noradrenaline fibers arising from the locus coeruleus (Itakura et al., 1981; Watabe et al., 1982; reviewed in Saper, 1984). Correspondingly, this region exhibits high densities of $\alpha$ - and $\beta$-adrenergic receptors $(\alpha \mathrm{AR}$, $\beta A R$ ) (Jonsson and Kasamatsu, 1983; Rainbow et al., 1984; Jones et al., 1985; Aoki et al., 1986). Upon release, noradrenaline modulates the ratio of stimulus-driven activity relative to spontaneous activity (Saper, 1984; reviewed in Foote and Morrison, 1987). This modulation is thought to play an important role in determining cortical neurons' sensitivity to sensory stimuli (reviewed in Foote and Morrison, 1987) and in permitting activity-dependent alterations at excitatory synapses (Neuman and Harley, 1983; Hopkins and Johnston, 1984; Stanton and Sarvey, 1985). Noradrenaline has also been suggested to promote plasticity in cat visual cortex during development via activation of $\beta$ AR (Bear and Singer, 1986; Gordon et al., 1990; reviewed in Kasamatsu, 1987). While these findings, together, suggest that interactions between excitatory transmitters and catecholamines may bring about long-lasting alterations in synaptic strength, little is known about the cellular circuitry that may underlie such phenomena.

Whether or not catecholamines, such as noradrenaline, mediate their action via morphologically identifiable synapses and/ or via a more diffuse "volume" transmission remains an open issue (Descarries et al., 1991; reviewed in Fuxe and Agnati, 1991). In support of the latter view, we have previously shown that polyclonal antibodies directed against the whole $\beta \mathrm{AR}$ molecule of frog erythrocytes $\left(\beta_{2}\right.$-type) recognize discrete patches of astrocytic plasma membrane as well as dendritic plasma membranes that both lack and exhibit synaptic specializations (Aoki et al., 1987). More recent studies have indicated that a monoclonal antibody directed against the third intracellular loop (amino acids 226-239) of hamster lung $\beta \mathrm{AR}\left(\beta_{2}\right.$-type) recognizes neuronal perikarya and dendrites but virtually none of the astrocytes (Aoki et al., 1989; Aoki and Pickel, 1990). In contrast, a polyclonal antibody directed against the intracellular, C-terminal tail (amino acids 404-418) recognizes neither neuronal perikarya nor dendrites but, instead, reacts with membranes of astrocytic processes in the brainstem of adult rats (Aoki \& Pickel, 1992a,b). Since many of these astrocytic processes interleave 


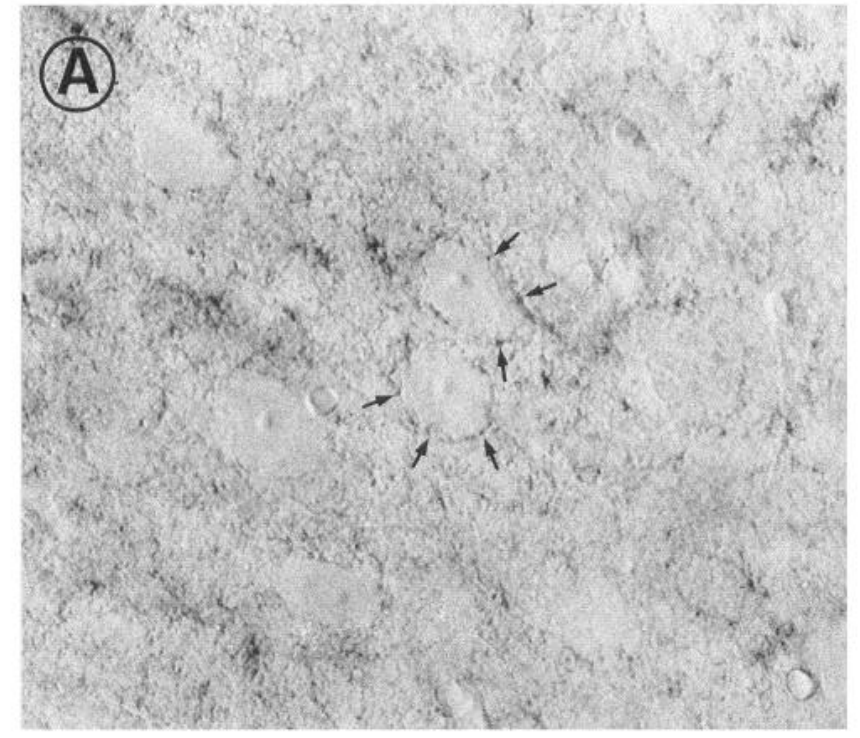

\section{(B)}
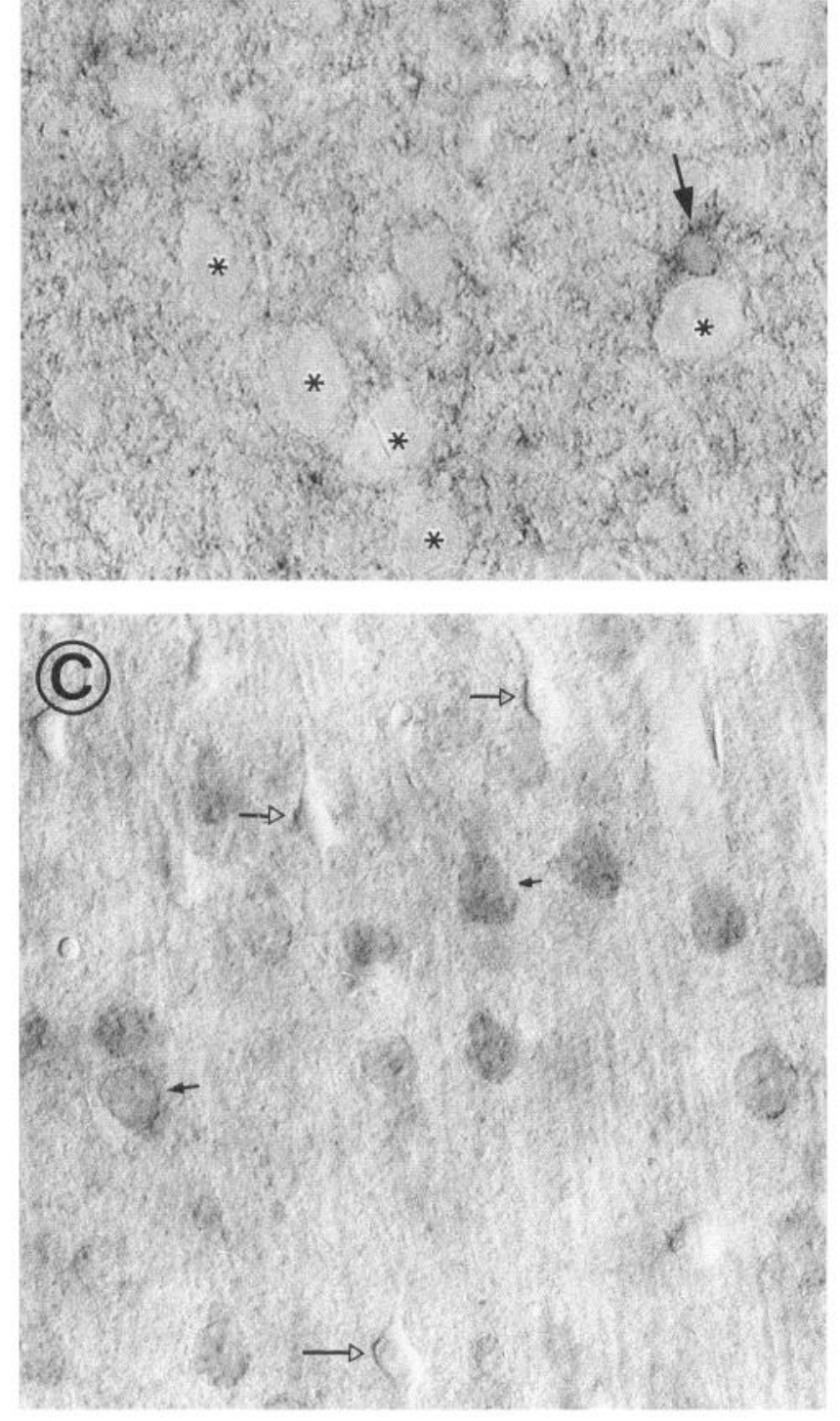

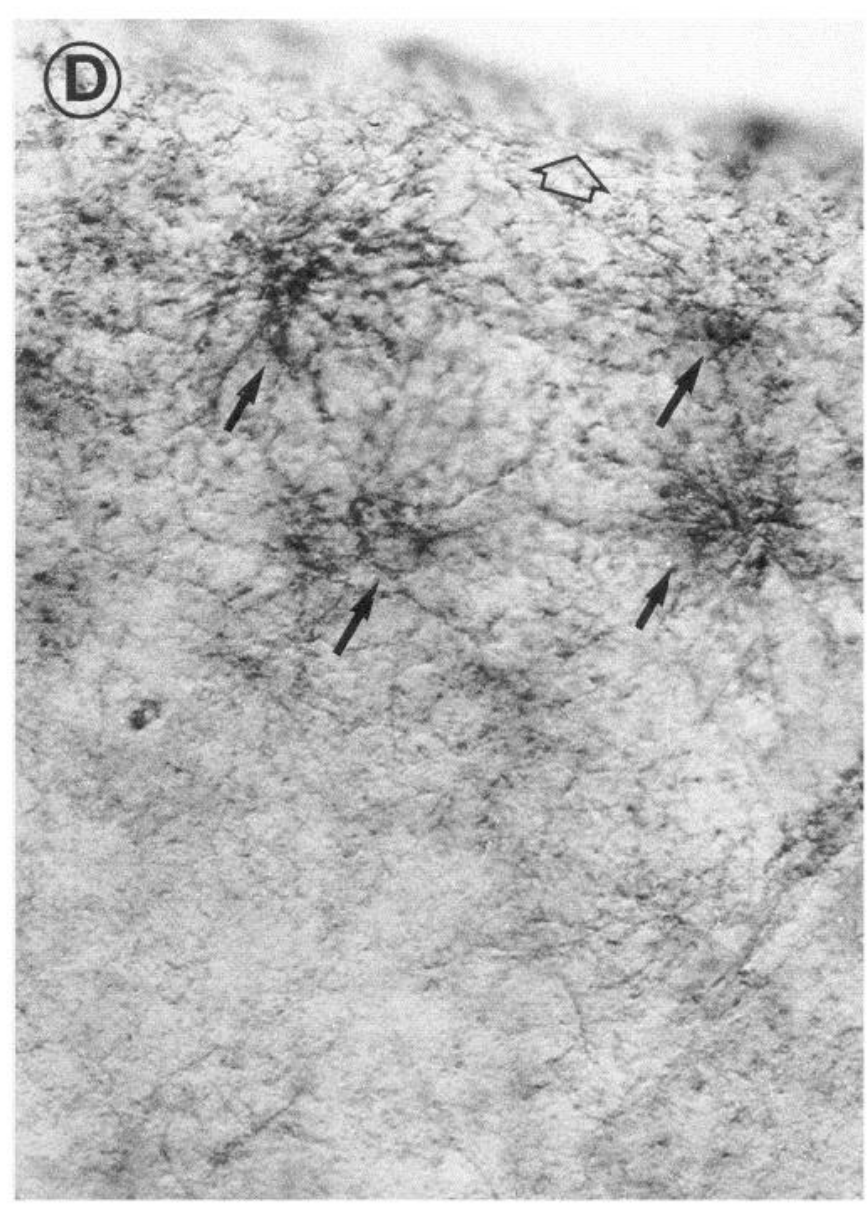

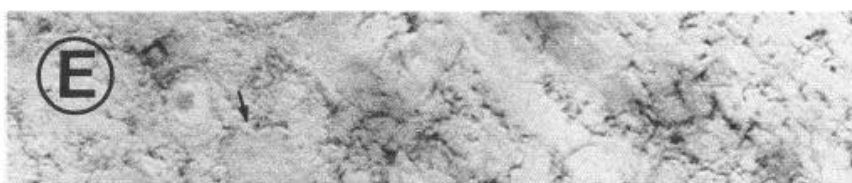

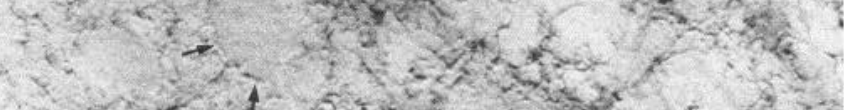

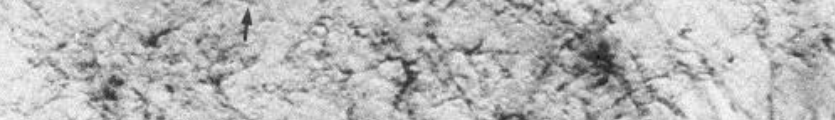

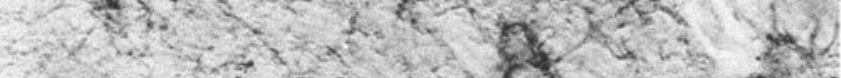

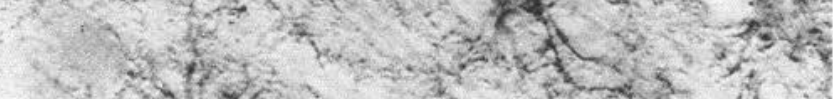

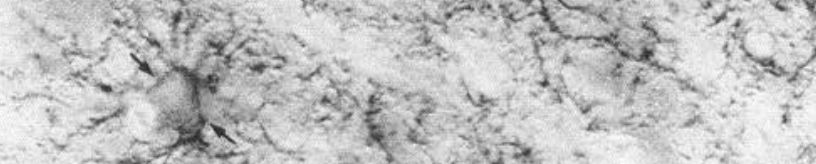

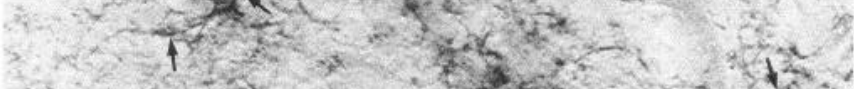

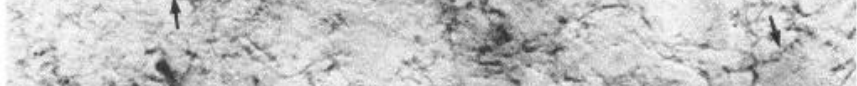

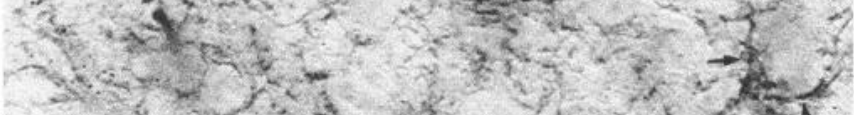

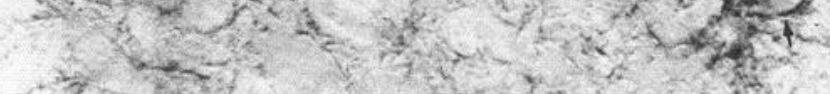

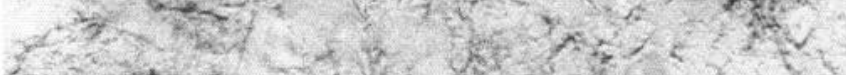

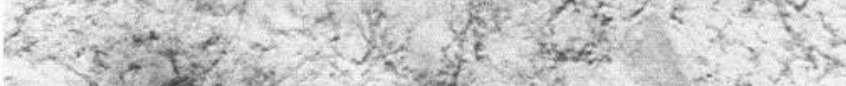

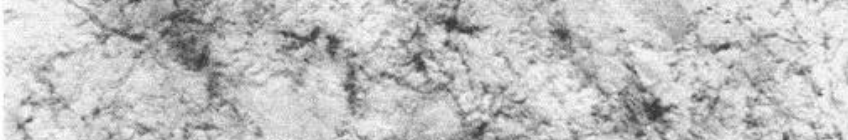

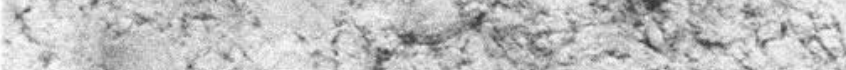

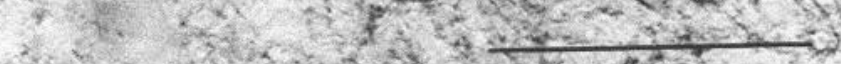


between catecholamine and noncatecholamine nerve cell bodies, we hypothesized that astrocytic $\beta \mathrm{AR}$ may be targets for catecholamines released from neuronal perikarya or dendrites (Aoki and Pickel, 1992a,b). The present study sought (1) to determine whether or not other areas, such as the supragranular laminac of visual cortex, which lack catecholamine perikarya, also contain astrocytes that express $\beta \mathrm{AR}$; and (2) to identify the ultrastructural relations between astrocytic $\beta \mathrm{AR}$ and catecholamine axons and (3) between astrocytic $\beta \mathrm{AR}$ and asymmetric axospinous synapses where excitatory neurotransmissions presumably occur (Gray, 1959; Somogyi et al., 1986; Morrison et al., 1989).

Preliminary results of this study were reported at the Society for Neuroscience annual meeting in 1990.

\section{Materials and Methods}

Source of antibodies. Antibodies against $\beta \mathrm{AR}$ were generous gifts from Dr. C. D. Strader of Merck Sharp and Dohme Research Laboratories (Rahway, New Jersey). These antibodies were directed against synthetic pcptides corresponding to amino acids $248-256$ and $404-418$ of hamster lung $\beta_{2}$-adrenergic receptors ( $\beta$ AR248 and $\beta$ AR404) (Dixon et al., 1986). The specificity of $\beta$ AR 404 for the $\beta$ AR molecule has been demonstrated earlier using the Western blot method (Strader et al., 1987a). Specificity of antibodies against $\beta$ AR404 and $\beta$ AR248 was also demonstrated by immunoprecipitation of radiolabeled $\beta$ AR (Strader et al., 1987b). Mouse monoclonal antibody against tyrosine hydroxylase $(\mathrm{TH})$ was purchased from Boehringer-Mannheim Biochemical. Biotinylated goat anti-rabbit IgG and streptavidin-peroxidase complex (ABC Elite kit) were from Vector Laboratories. The $1 \mathrm{~nm}$ gold-labeled goat anti-mouse $\mathrm{IgG}$ and Silver IntenSEM kit were purchased from Amersham.

Preparation of brain tissue. Four random source adult cats were deeply anesthetized using ketamine $(22 \mathrm{mg} / \mathrm{kg}$, i.m.), acepromazine $(0.1 \mathrm{mg} /$ $\mathrm{kg}$, i.m.), and Nembutal $(30 \mathrm{mg} / \mathrm{kg}$, i.v.), and then perfused through the ascending aorta with $30 \mathrm{ml}$ of heparin/saline mixturc $(1000 \mathrm{U} / \mathrm{ml}$; Wyeth) and then with 1 liter of $4 \%$ paraformaldehyde buffered with $0.1 \mathrm{M}$ phosphate buffer (PB; pH 7.4) under artificial ventilation. Ten adult Sprague-Dawley rats were anesthetized with Nembutal (30 mg/kg, i.p.) and then perfused through the ascending aorta with $10 \mathrm{ml}$ of heparin/ saline $(1000 \mathrm{U} / \mathrm{ml})$, followed by $50 \mathrm{ml}$ of $0.1 \mathrm{M} \mathrm{PB}$ containing $3.75 \%$ acrolein, $2 \%$ paraformaldehyde (King et al., 1983), and then by $300 \mathrm{ml}$ of $2 \%$ paraformaldehyde in $0.1 \mathrm{M} \mathrm{PB}$. Aldehyde-fixed cat and rat brain slabs containing area 17 were sectioned at a thickness of $40 \mu \mathrm{m}$ using a Vibratome and collected in $0.1 \mathrm{M}$ PB. Rat sections that were fixed with acrolein/paraformaldehyde were immersed in $1 \%$ sodium borohydride for $30 \mathrm{~min}$ and then rinsed repeatedly with $0.1 \mathrm{M} \mathrm{PB}$ until bubbles on tissue surface disappeared. Sections were then rinsed in $0.1 \mathrm{M}$ Trisbuffered saline (TBS; pH 7.6) and incubated in a blocking solution consisting of $1 \%$ bovine serum albumin (BSA; Sigma) in TBS for at least $30 \mathrm{~min}$.

Immunocytochemistry. Single labeling for $\beta \mathrm{AR} 404$ and $\beta \mathrm{AR} 248$ was achieved by the avidin-biotin complex (ABC) immunoperoxidase method of Hsu (Hsu et al., 1981). Free-floating sections were incubated under gentle agitation at room temperature for 12-16 hr in TBS containing 1\% BSA and 1:2000-1:10,000 dilutions of the primary antibodies. Triton X-100 (0.3\%) was included with the primary antibody dilutions when preparing tissues for light microscopy. At the end of the incubation period, sections were rinsed in TBS, incubated for $30 \mathrm{~min}$ with 1:200 dilution of biotinylated goat anti-rabbit $\mathrm{IgG}$, and then incubated with the streptavidin-peroxidase complex for another $30 \mathrm{~min}$. Peroxidase was visualized by incubating tissues for $6 \mathrm{~min}$ in TBS con- taining $0.022 \% 3,3^{\prime}$-diaminobenzidine (Aldrich) and $0.003 \% \mathrm{H}_{2} \mathrm{O}_{2}$. All incubations were preceded and followed by rinses in TBS. Cat tissue fixed with $4 \%$ paraformaldehyde was postfixed with $2 \%$ glutaraldehyde in PBS before processing for electron microscopy.

Simultaneous labeling for $\beta$ AR404 and TH within rat visual cortex was achieved by using a previously described method (Chan et al., 1990). In brief, Vibratome sections were incubated overnight in a TBS/BSA buffer containing primary antibodies against $\beta$ AR404 and TH diluted to $1: 5000$ and $1: 1$, respectively. On the following day, sections first were reacted for the immunocytochemical detection of $\beta$ AR 404 by the ABC method. Subsequently, sections were incubated for $3 \mathrm{hr}$ in a buffer consisting of $0.01 \mathrm{M}$ phosphate buffer (pH 7.3) with $0.9 \%$ sodium chloride (PBS), $1 \%$ BSA, and $2 \%$ gelatin (Amersham) (PBS/BSA/G) and containing 1:50 dilution of gold-labeled goat anti-mouse IgG and 1\% goat serum. At the end of the $3 \mathrm{hr}$ incubation period, sections were rinsed for $5 \mathrm{~min}$ in the same buffer under gentle agitation and then three times in PBS. Sections were postfixed for $10 \mathrm{~min}$ at room temperature using $2 \%$ glutaraldehyde (EM grade, EM Sciences) buffered with PBS. These sections were rinsed again in PBS to remove free glutaraldehyde. Following brief immersion in distilled water, sections were silver intensified for 5-7 min in acid-cleaned porcelain spot dishes using the light-insensitive IntenSE Kit at room temperature. The silver-intensification step was terminated by rinsing sections in distilled water; they were then returned to PBS.

Electron microscopy. Following further fixation for $1 \mathrm{hr}$ with $2 \%$ osmium tetroxide in $0.1 \mathrm{M}$ phosphate buffer, sections were prepared for electron microscopy using previously described methods (Chan et al., 1990). In brief, sections were dehydrated using ethanol, flat embedded in Epon 812 using fluoroplastic coverslips (Masurovsky and Bunge, 1968 ), and then reembedded in Beem capsules. No more than $50 \mathrm{ul}$ trathin sections were collected from surfacemost regions of the block. Ultrathin sections were viewed under a Philips 201 electron microscope following counterstaining with uranyl acetate and lead citrate.

\section{Results}

\section{Distribution of $\beta A R$ immunoreactivity as revealed by light microscopic immunocytochemistry}

In the cat visual cortex, Nomarski differential interference contrast optics revcaled immunoreactivity for $\beta$ AR 404 within cells that appeared astrocytic (Fig. 1). Numerous processes that radiated from single, small cell bodies were intensely labeled, particularly within laminae I and V/VI. Also labeled were numerous small, punctate processes. Within the deeper laminae, many of the processes appeared to form baskets around larger perikarya. This pattern of labeling persisted through the different dilutions of the antibody. Immunoreactivity to $\beta$ AR248 was not detectable within the cat visual cortex at any of the tested dilutions.

In the rat visual cortex, punctate, brown labeling reflecting $\beta$ AR404 immunoreactivity was evident throughout the laminae. These labeled puncta were distributed evenly throughout the neuropil and surrounded large, apparently neuronal, perikarya that lacked immunoreactivity for $\beta A R 404$ (Fig. 1). Intensity of peroxidase labeling within the neuropil varied according to the dilution of the antibody. However, the pattern of staining, including the lack of labeling within perikarya, remained constant throughout the dilutions. The semiadjacent sections that were immunolabeled with the $\beta$ AR 248 antibody

Figure 1. Light microscopic visualization of $\beta \mathrm{AR}$ immunoreactivity within the visual cortex of rat (left column) and cat (right column). Left column, $A$ and $B$ show immunoreactivity using the $\beta$ AR404 antiserum while $C$ shows immunoreactivity following the application of the $\beta$ AR 248 antiserum. $\beta$ AR 404 immunoreactivity is detectable within punctate processes (arrows in $A$ ) and small cell bodies (arrow in $B$ ) that surround unlabeled perikarya (asterisks in cytoplasm in $B$ ) and throughout the laminae of visual cortex. $\beta$ AR248 immunoreactivity occurs within perikarya ( $C$, solid arrows) that are admixed with unlabeled perikarya ( $C$, open arrows). Right column, $D$ and $E$ show $\beta A R 404$ immunoreactivity within the supraand infragranular layers, respectively. Immunoperoxidase labeling is distributed throughout radiating processes that originate from small cell bodies (solid arrows in $D$ ) and run in all directions. Some of the processes appear to encircle unlabeled perikarya (arrows in $E$ ). The open arrow in $D$ points to the pial surface. Scale bar, $50 \mu \mathrm{m}$. 

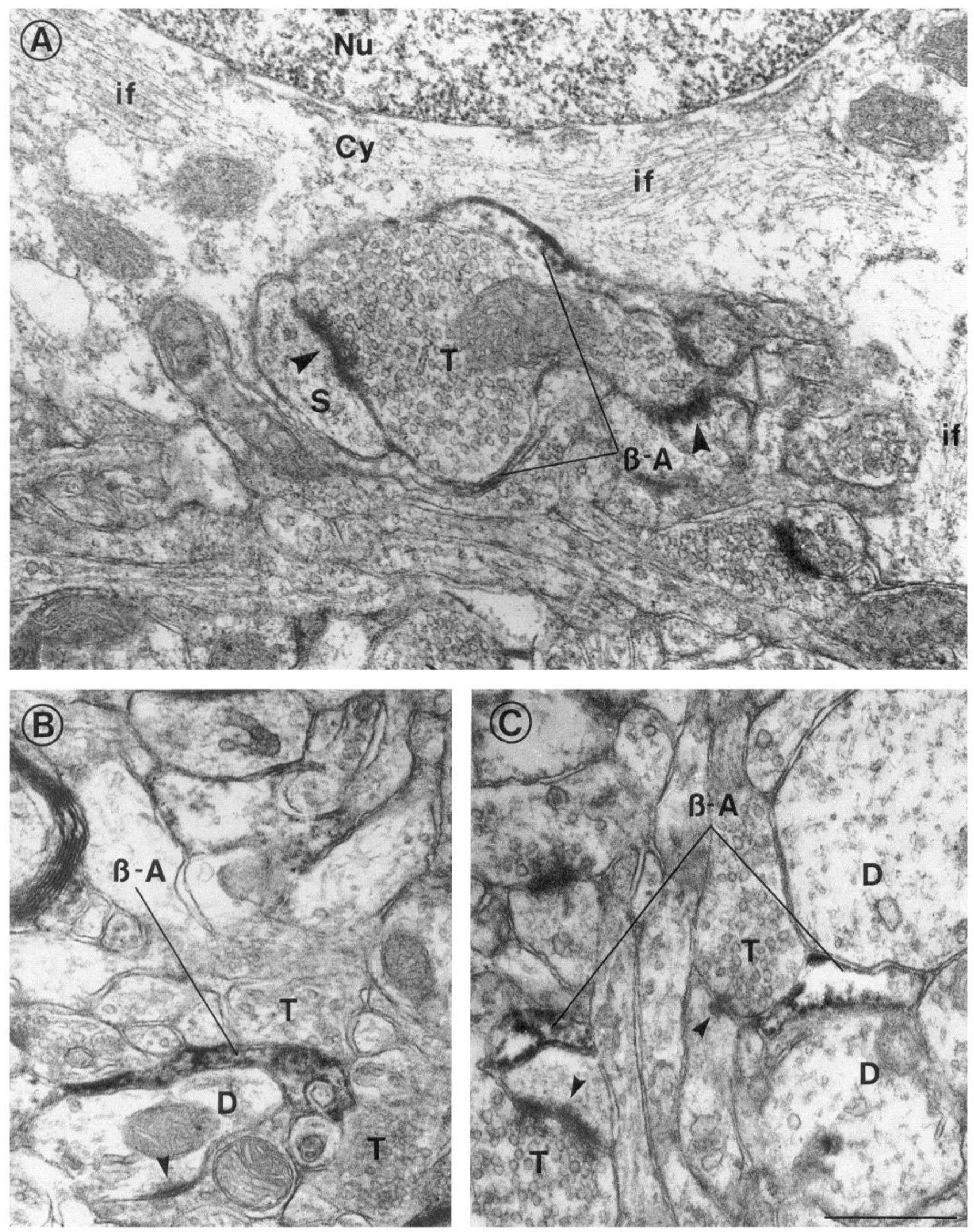

Figure 2. Ultrastructural localization of $\beta$ AR404 within the cat visual cortex. The electron micrographs in $A-C$ show that $\beta$ AR404 immunoreactivity occurs within small processes that appear astrocytic. Unlike the round profiles of axon terminals $(T)$, dendrites $(D)$, and dendritic spines $(S)$ (arrowheads point to postsynaptic densities within dendrites and spines), the $\beta$ AR404-immunoreactive processes $(\beta-A)$ have irregular contours that tightly ensheathe the neuronal processes. The cytoplasm $(\mathrm{Cy})$ of an astrocytic cell body $(\mathrm{Nu}$, nucleus) in $\mathrm{A}$ contains glial fibrillary acidic protein filaments (if) but no immunoreactivity for $\beta$ ar404. Scale bar, $0.5 \mu \mathrm{m}$. 
revealed immunoreactivity that was most intense within large neuronal perikarya (Fig. 1). Smaller, unlabeled perikarya were admixed with the larger, immunoreactive perikarya in the same region.

\section{Distribution of $\beta A R 404$ as revealed by electron microscopic immunocytochemistry}

In the cat visual cortex, immunoreactivity for $\beta$ AR404 was found within processes that appeared astrocytic based on their irregular contours surrounding synaptic junctions (Fig. 2) (Peters et al., 1991). Immunoreactivity within these processes appeared as flocculent material coating the intracellular surface of plasma membranes. In some cases, fine, apparently distal, astrocytic processes containing $\beta$ AR404 immunoreactivity were juxtaposed to larger-caliber proximal processes and perikarya of astrocytes that contained large bundles of intermediate-filament bundles but no $\beta$ AR404 immunoreactivity (Fig. 2). $\beta$ AR404immunoreactive astrocytic processes frequently surrounded axon terminals forming asymmetric synaptic junctions with small dendritic spines (Fig. 2).

In the rat visual cortex, $\beta \mathrm{AR} 404$ immunoreactivity also occurred in fine processes with irregular contours that appeared to be distal portions of astrocytes. These processes surrounded axons, dendrites, and axodendritic synaptic junctions. Immunoreactivity within astrocytic processes resembled that observed in the cat visual cortex in that the reaction product appeared attached to the intracellular surface of plasma membranes (Figs. 3-6). In sections dually labeled for $\beta A R 404$ and TH, immunoperoxidase reaction product reflecting the presence of $\beta A R 404$ was clearly distinguishable from the clusters of silver-intensified gold particles overlaying axons (Figs. 3-6). Axonal profiles containing catecholamine exhibited numerous small clear vesicles. Some, but not all, also contained large dense-cored vesicles.

$\beta A R 404$-immunoreactive astrocytic processes juxtaposed to catecholamine terminals. Numerous axospinous junctions were identified within the supragranular laminae of rat visual cortex. The majority of these synaptic junctions were asymmetric [Gray type 1 (Gray, 1959)], lacked TH immunoreactivity presynaptically, and also lacked $\beta A R 404$ immunoreactivity on either side of the synapse. However, these unlabeled synapses often were encapsulated by fine astrocytic processes exhibiting $\beta$ AR404 immunoreactivity along the intracellular surface (Fig. 3). Contacts between $\mathrm{TH}$-immunoreactive varicosities and dendrites were identified by the following morphological characteristics: parallel alignment between the plasma membranes of the axon terminal and dendrite or spine, accumulation of small clear vesicles within the immunoreactive terminal, and postsynaptic specializations that tended to be less dense than those associated with the neighboring unlabeled terminals (Fig. 3). Most catecholamine axonal varicosities showed no identifiable synaptic junctions within single planes of sections (Fig. 4). However, they were frequently juxtaposed to $\beta$ AR404-immunoreactive astrocytic processes (Fig. 4). As observed in the cat visual cortex, $\beta$ AR404-immunoreactive astrocytic processes also surrounded asymmetric axospinous junctions that lacked immunoreactivity for TH or for $\beta A R 404$ (Figs. 3, 4). The $\beta A R 404$ labeling along the plasma membrane of astrocytic processes usually extended beyond the portion juxtaposed to catecholamine varicosities. Some catecholamine varicosities formed small, symmetric contacts that showed little besides the parallel alignment of the two plasma membranes as the identifiable features of synaptic specializations (Fig. 5). This latter type of terminal contained only a few vesicles and was not directly juxtaposed to $\beta$ AR404-immunoreactive astrocytic processes. Instead, $\beta A R 404-i m m u-$ noreactive astrocytic processes in their near vicinity were adjacent to other terminals forming asymmctric synaptic junctions. Other TH-immunoreactive terminals forming junctions with larger dendrites showed synaptic specializations that were more easily identifiable. Numerous small clear vesicles were clustered near the presynaptic membrane, and both the pre- and postsynaptic membranes showed slightly enhanced electron density and parallel alignment with each other (Fig. 6). These TH-containing synaptic terminals were directly contacted by $\beta$ AR404immunoreactive astrocytes.

BAR404-immunoreactive astrocytes and TH-immunoreactive terminals near blood vessels. TH-immunoreactive terminals forming junctions with large dendrites were found near small blood vessels that were surrounded by astrocytic processes showing variable degrees of immunoreactivity for $\beta$ AR 404 (Fig. 6). The $\beta \mathrm{AR} 404$-immunoreactive astrocytic processes often were interposed between the catecholamine axon terminals and the basement membrane of blood vessels.

\section{Discussion}

Light and electron microscopic observations of adult area 17 support the following conclusions: (1) in both rats and cats, BAR404 immunoreactivity occurs in highest density along the intracellular surface of plasma membranes of distal astrocytic processes; (2) $\beta$ AR248 immunoreactivity within the rat visual cortex is localized to neuronal perikarya and proximal dendrites, as was previously observed using another antibody against the third intracellular loop (Aoki et al., 1989); (3) BAR404-immunoreactive astrocytes occur juxtaposed to catecholamine axon terminals forming large synaptic junctions; (4) $\beta A R 404-i m-$ munoreactive astrocytes also occur removed from catecholamine-axons exhibiting paucity of vesicles and small, less obvious synaptic specializations; (5) astrocytes forming end feet along blood vessels contain $\beta$ AR404 immunoreactivity. The possible significance of these observations is discussed below and schematized in Figure 7.

\section{Methodological considerations}

Specificity of the antibodies. Antibodies available for this study were directed against two synthetic peptides, each conjugated to thyroglobulin using aldehydes. The searches for homologous sequences by the method of Pearson and Lipman (1988) showed that the sequence of these peptides was unique among all proteins so far reported and stored in GenBank, EMBL, SWISSPROT, and GenPept databases. These included all of the G-protein-linked proteins and monoamine transporters so far cloned. However, similar sequences may occur within other, yet unidentified, proteins. These may include proteins that do not functionally bind norepinephrine. Thus, immunoreactivity that was detected in the present study is interpreted to reflect the presence of $\beta \mathrm{AR}$ or some other $\beta \mathrm{AR}$-like molecule(s), even if not so specified in the Discussion.

Immunocytochemical detectability. Based on comparative examinations of the hydropathicity profiles of $\beta A R$ and rhodopsin, the C-terminal tail of $\beta A R$ was predicted to reside within the intracellular domain (Dixon et al., 1986). The present findings confirmed this prediction, since the ultrastructural distribution of $\beta$ AR404 immunoreactivity reflected highest levels along the intracellular surface of plasma membranes. The relative ease 

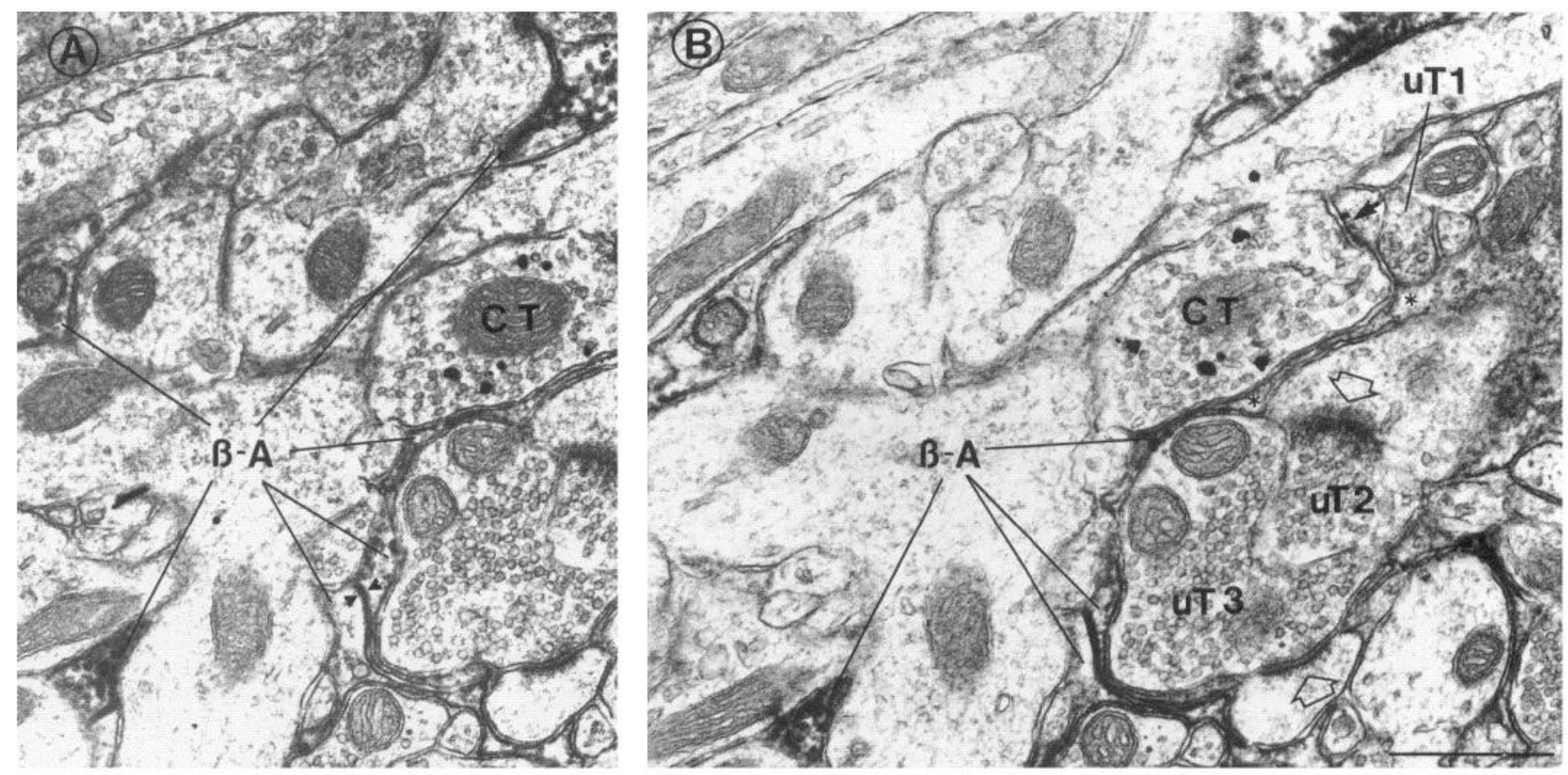

Figure 3. Electron micrographs showing $\beta$ AR404-immunoreactive astrocytic processes that encircle one catecholamine varicosity and two unlabeled synaptic terminals. These electron micrographs were obtained from serially collected ultrathin sections of the rat visual cortex. In $A$, two of the $\beta$ AR404-immunoreactive processes $(\beta-A)$ form gap junctions with each other (arrowhead pair). In $B$, portions of the lower right astrocytic process (asterisks in the cytoplasm) course next to the terminal identifiable as catecholamine-containing by the presence of silver-intensified gold particles reflecting immunoreactivity to TH. Catecholamine-containing terminal $(C T)$ forms a contact with a small dendritic spine (solid arrow in $B$ ). Three unlabeled terminals $(u T 1, u T 2$, and $u T 3)$ also are juxtaposed to the $\beta$ AR404-immunoreactive astrocytic process. Open arrows in $B$ point to postsynaptic densities within dendritic spines that are associated with $u T 2$ and $u T 3$. Scale bar, $0.5 \mu \mathrm{m}$.

with which $\beta$ AR could be detected in the present study is likely to reflect, at least in part, the accessibility of immunoreagents to this hydrophilic portion. Had the antigen belonged to a hydrophobic region, immunodetection for electron microscopy may not have been possible. In order to further ensure optimal immunocytochemical detection, the sampling of ultrathin sections for electron microscopy was carefully restricted to the surfacemost portions of Vibratome sections. Within dually labeled sections, ultrastructural analysis was further restricted to regions that showed both peroxidase reaction product and immunogold labeling. However, the immunocytochemical technique is limited in that one cannot determine whether or not absence of immunoreactivity reflects absence, lower levels, or diminished accessibility of the molecule to immunoreagents.

By an analogous reasoning, the absence of $\beta$ AR2 248 labeling within the cat visual cortex may reflect levels of $\beta$ AR that are too low for detection. Alternatively, the cat $\beta$ AR may exhibit substantial differences in their amino acid sequences when compared to the hamster lung type or the rat neuronal form of $\beta A R$. On the other hand, the absence of labeling is not likely to reflect lack of accessibility of the sites to immunoreagents, since (1) the same cat tissue could be labeled with the $\beta A R 404$ antiserum, and (2) rat tissues fixed with stronger aldehydes, such as acrolein (King et al., 1983), still exhibited immunocytochemical labeling for $\beta$ AR404.

Difference in $\beta A R 404$ labeling between rat and cat visual cortex. $\beta$ AR 404 labeling of astrocytes was more prominent in the cat than in rat visual cortex. This difference was most likely due to the use of different fixatives in the two species. Four percent paraformaldehyde that was used for cat tissue cross-links pro- teins much more slowly and less extensively than the $3.75 \%$ acrolein-2\% paraformaldehyde mixture that was used for rat tissue (Hayat, 1981). Thus, the more extensive labeling seen for the cat visual cortex may reflect greater diffusion of antigen during the fixation process or greater accessibility of the immunoreagents to the antigenic site.

\section{Astrocytic localization of $\beta A R 404$ immunoreactivity}

Many in vitro studies have pointed to the presence of astrocytic $\beta$ AR (Burgess and McCarthy, 1985; reviewed by Stone and Ariano, 1989) that are functionally coupled to adenylate cyclase (Rougon et al., 1983; Bicknell et al., 1989; Stone et al., 1990). However, the present study is the first to show that astrocytes in intact visual cortex also express $\beta \mathrm{AR}$.

The absence of $\beta$ AR 404 immunoreactivity within neurons might not have been expected, since previous pharmacological studies have demonstrated a catecholamine modulation of neuronal excitability (Madison and Nicoll, 1982; reviewed by Foote and Morrison, 1987). Most likely, $\beta$ AR in adult cerebral cortex do occur in neurons but in a form (or forms) that is not recognizable by the $\beta$ AR 404 antibody. Hamster lung $\beta_{2}$ AR may be more homologous with $\beta \mathrm{AR}$ of astrocytes within the C-terminal region but more homologous with neuronal $\beta \mathrm{AR}$ in the third intracellular loop region of rat and cat brains. Interestingly, the recently discovered $\beta_{3}$-adrenergic receptor also shows notable diversification in the $\mathrm{C}$-terminal region (Emorine et al., 1990). This implies that $\beta A R$ may occur in different forms within the CNS and that these different forms are distributed differentially across neurons and astrocytes. This idea predicts that the gene(s) for neuronal $\beta \mathrm{AR}$ may be different from those 

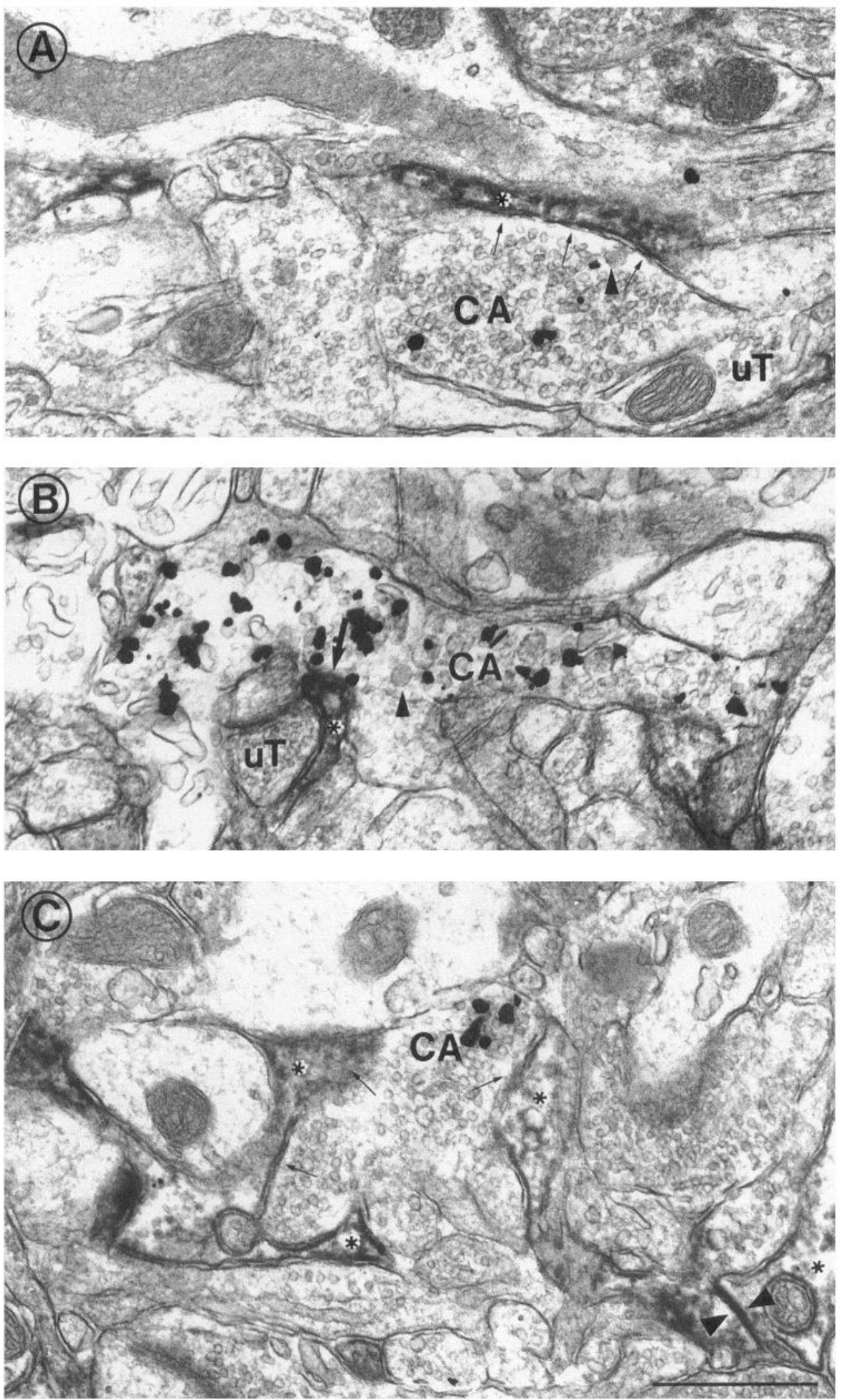

Figure 4. Dual electron microscopic immunocytochemical labeling for catecholamine axon varicosities and $\beta A R 404$ within the rat visual cortex. The catecholaminergic axon varicosities $(C A)$ labeled by the silver-intensified immunogold method using anti-TH are identifiable by the accumulation of electron-dense particles within the cytoplasm. Most of the vesicles that occur within these varicosities are small and clear. However, a few larger, densecored vesicles also are evident (arrowheads in $A$ and $B$ ). Immunoperoxidase labeling reflecting $\beta$ AR 404 immunoreactivity occurs within the cytoplasm and along the plasma membrane of astrocytes (asterisks). Small arrows in $A$ and $C$ point to portions of $\beta$ AR404immunoreactive astrocytic processes that are juxtaposed to the catecholamine varicosities. Arrowhead pair in $C$ points to a gap junction formed between two $\beta$ AR 404-immunoreactive astrocytic processes. Scale bar, $0.5 \mu \mathrm{m}$. of astrocytic $\beta$ AR. Alternatively, the $C$-terminal portion of neuronal $\beta$ AR may be rendered unrecognizable by the $\beta$ AR 404 antibody due to posttranslational modification, such as phosphorylation (Sibley and Lefkowitz, 1985; Bouvier et al., 1988) and truncation. Another possibility is that the association of $\beta$ AR with other molecules, such as the GTP-binding proteins (Sibley and Lefkowitz, 1985) and $\beta$-arrestin (Lohse et al., 1990), differs between neurons and astrocytes in such ways as to cause differential steric hindrance for antibody recognition.

Recent preliminary results indicate that the $\beta$ AR 404 antibody 

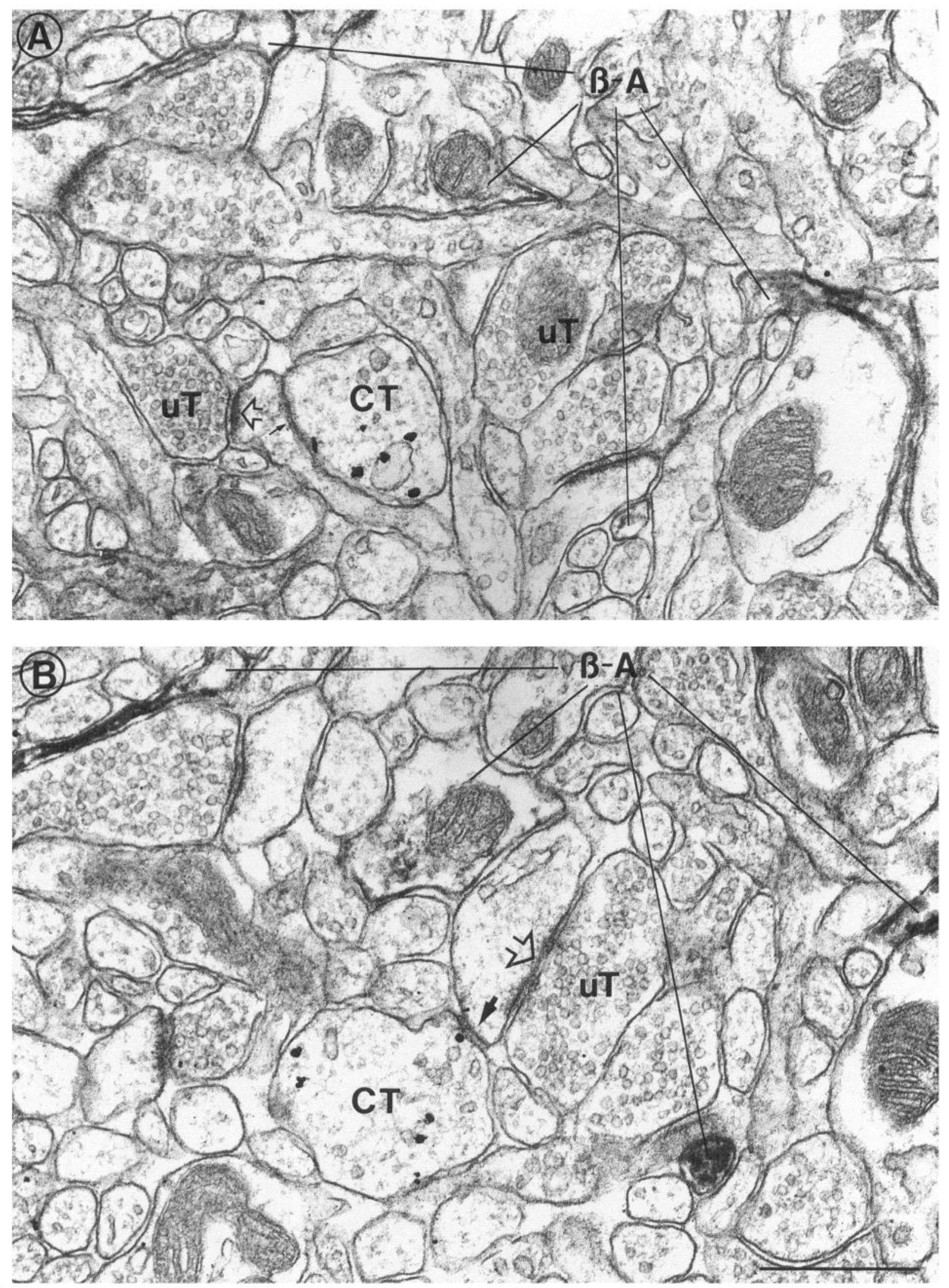

Figure 5. Electron micrographs obtained from semiadjacent ultrathin sections showing the relation between $\beta$ AR404-immunoreactive astrocytic processes and a catecholamine terminal containing few vesicles. The gold-labeled catecholamine terminal $(C T)$ forms a small axospinous symmetric contact with a dendritic spine (solid arrow in $B$ points to the postsynaptic membrane). This junction is not evident in $A$. The same spine receives synaptic input from an unlabeled terminal $(u T)$. Open arrows in $A$ and $B$ point to the thick postsynaptic densities that are associated with unlabeled terminals. There are several unlabeled processes between the $\beta$ AR404-immunoreactive astrocytic processes $(\beta-A)$ and catecholamine terminals (CT). Scale bar, $0.5 \mu \mathrm{m}$. 

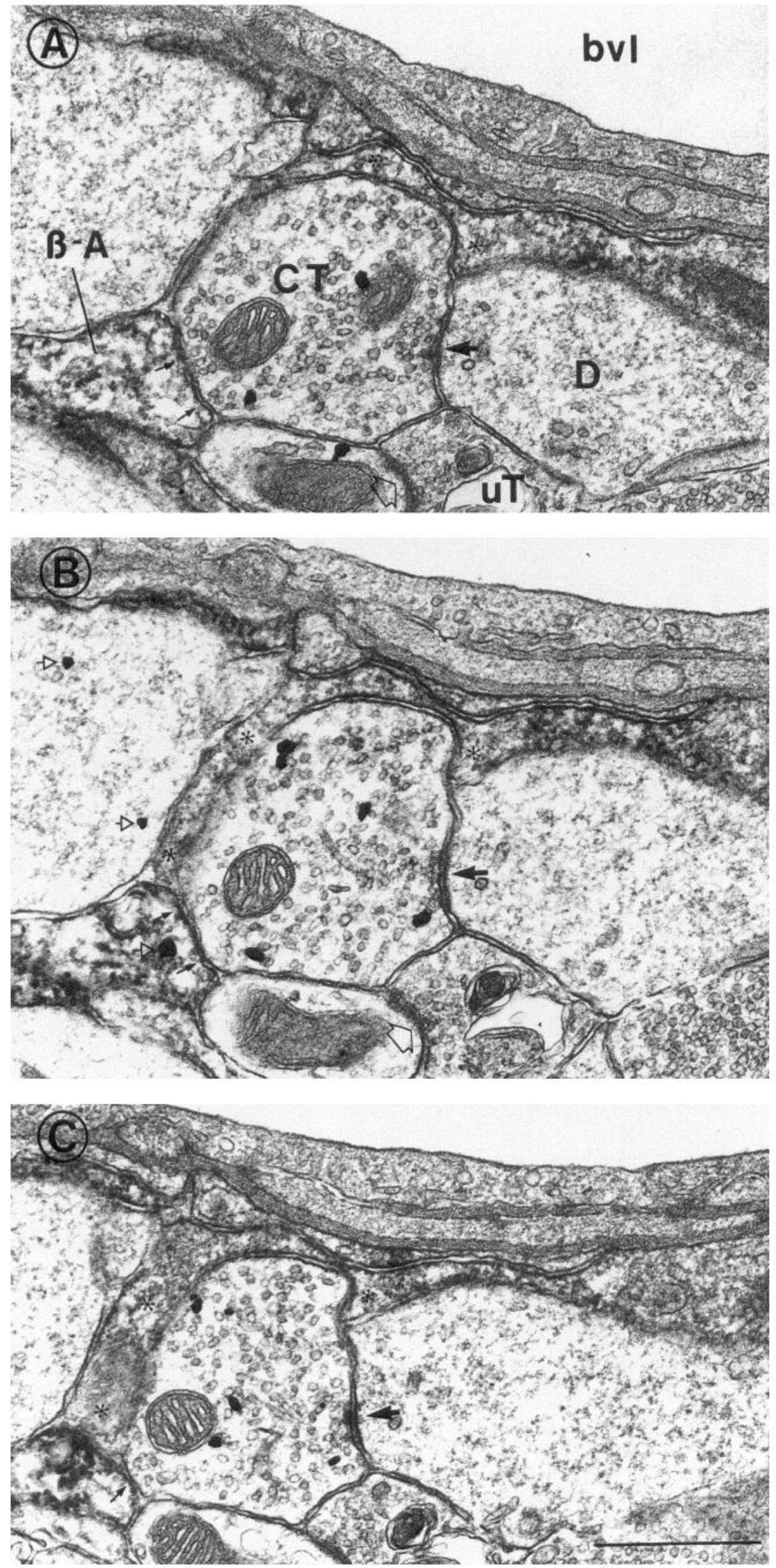

Figure 6. Serial electron micrographs showing the relation between a synaptic catecholamine terminal $(C T)$, a blood vessel $(b v l)$, and several $\beta$ AR404-immunoreactive astrocytic processes $(\beta-A)$ in the rat visual cortex. Silver-intensified gold particles recur within the cytoplasm of the terminal $(C T)$. In all of these sections (large solid arrows in $A-C$ ), this terminal forms a symmetric synaptic junction with an unlabeled dendrite ( $D$ in panel $A$ ). Astrocytic processes that course above (asterisks in cytoplasm) and below (small solid arrows point to contact sites with $C T$ ) show peroxidase reaction product reflecting $\beta$ AR404 immunoreactivity. Small open arrow $(B)$ points to nonrecurring silver grains that probably reflect background labeling. Large open arrows $(A, B), u T$, unlabeled terminal that is presynaptic to a dendrite's postsynaptic density. Scale bar, $0.5 \mu \mathrm{m}$. 


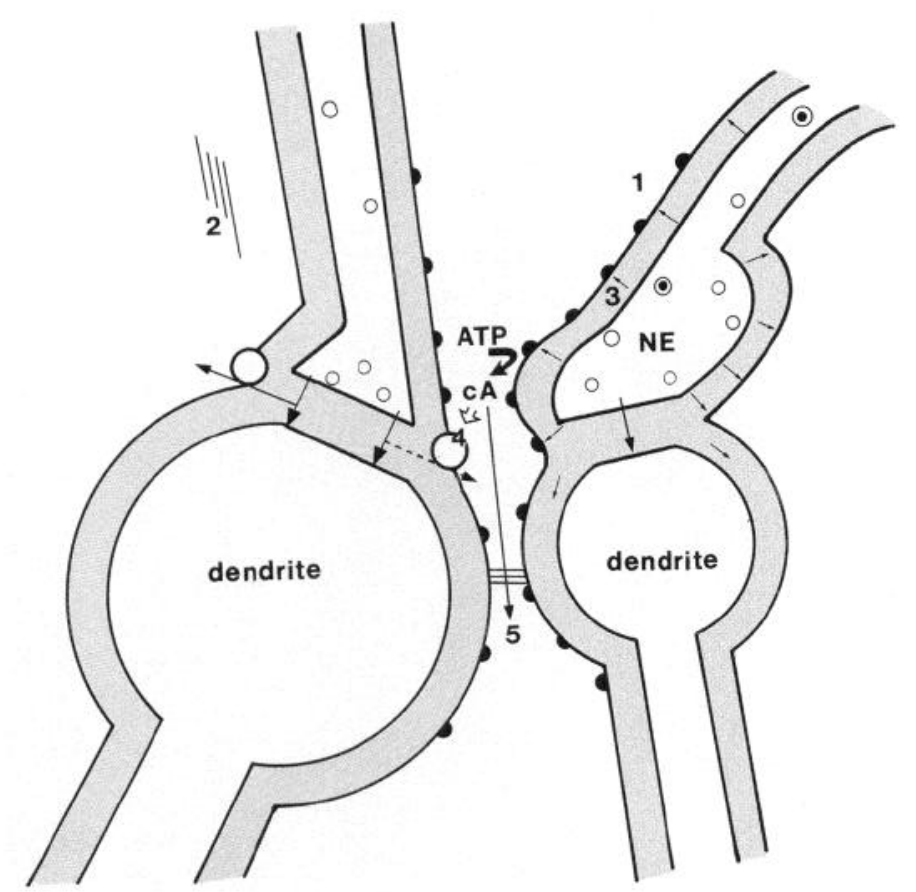

Figure 7. A schematic drawing summarizing the ultrastructural basis for functional interactions between astrocytes and neurons. Circles represent vesicles contained in axon terminals. $\beta$ AR 404 immunoreactivity (solid semicircles) occurs in high concentrations within fine astrocytic processes (1). $\beta$ AR404 immunoreactivity is not detectable within larger astrocytic processes containing intermediate filaments (2). Noradrenaline $(N E)$ may be released from portions of the axon lacking morphologically identifiable synaptic junctions but, instead, associated with astrocytes (3). The activation of $\beta$ AR on astrocytes may stimulate adenylate cyclase, leading to the elevation of cAMP $(c A)$ concentration. The elevation of CAMP concentration within astrocytes may inhibit the uptake of transmitters by the astrocyte (4) or enhance the permeability of gap junctions (5).

does recognize $\beta \mathrm{AR}$ of neurons, but only within discrete developmental stages (prior to $10 \mathrm{~d}$ postnatal ages in the cerebral cortex of rats). Since $\beta$ AR 404 immunoreactivity can be detected within perinatal tissue fixed with aldehydes (paraformaldehyde, glutaraldehyde, and acrolein), the absence of $\beta$ AR404 immunoreactivity within neurons of adult tissue is not likely to be attributed to fixation artifacts. However, the observations made in developing neural tissue could reflect age-dependent differences in the expression of different $\beta A R$ genes or of posttranslational modifications.

\section{Possible functions of $\beta A R$ at distal portions of astrocytes}

$\beta A R$ at astrocytic gap junctions. The present ultrastructural localization of $\beta$ AR404 immunoreactivity within the finer processes of astrocytes indicates that the distal portions of these cells may be specialized for $\beta$-adrenergic receptivity and the subsequent formation of cAMP via activation of adenylate cyclase (Rougon et al., 1983; Stone et al., 1990; reviewed by Stone and Ariano, 1989). One of the notable specializations at the labeled, distal ends of astrocytic processes was gap junctions formed with other astrocytic processes. The permeability of astrocytic gap junctions for ions and small molecules (including cAMP) is regulated by intracellular concentrations of $\mathrm{Ca}^{2+}$ and $\mathrm{H}^{+}\left(\left[\mathrm{Ca}^{2+}\right]_{i},\left[\mathrm{H}^{+}\right]_{i}\right)$ as well as cAMP (reviewed by Hertzberg et al., 1981; Spray et al., 1990). Since $\left[\mathrm{Ca}^{2+}\right]_{i}$ and $\left[\mathrm{H}^{+}\right]_{i}$ within astrocytes are subject to change following depolarization of neighboring neuronal membranes (Mugnaini, 1986; Chesler, 1990) and the direct transmitter-evoked depolarization of astrocytes (Hirata et al., 1983; Rougon et al., 1983; Bowman and Kimelberg, 1984; Usowicz et al., 1989; Cornell-Bell et al., 1990; reviewed by Barres et al., 1990), interaction between noradrenaline and non-noradrenaline neuronal elements in the neuropil may occur via their modulation of astrocytic gap junction permeability. Modulation of gap junction permeability, in turn, would be expected to have profound effects on the spatial characteristics of astrocytic buffering capacity of extracellular space (reviewed by Mugnaini, 1986) and consequently to influence neuronal excitability (reviewed by MacVicar et al., 1989; Chesler, 1990; Spray et al., 1990).

$\beta A R$ and astrocytic cytoskeleton. Astrocytes have been shown to respond to $\beta \mathrm{AR}$ activation with dramatic changes in their morphology (Narumi et al., 1978; Rougon et al., 1983; Shain et al., 1987; Bicknell et al., 1989). This response may involve the cAMP-dependent phosphorylation of intermediate-filament proteins, that is, glial fibrillary acidic protein (GFAP) (Browning and Ruina, 1984). However, the larger, presumably more proximal, processes that contained intermediate-filament bundles usually lacked $\beta$ AR404 immunoreactivity. Thus, the functional linkage between $\beta \mathrm{AR}$ activation and cAMP-dependent phosphorylation of GFAP may require the intracellular translocation of cAMP across significant distances within their processes or across gap junctions that adjoin distal processes with proximal portions of astrocytes. The morphological changes evoked by norepinephrine application may also involve reorganization of cytoskeletal proteins that are enriched within distal portions, such as spectrin (Zagon et al., 1986) and actin (reviewed by Kalnins et al., 1986).

$\beta A R 404$-immunoreactive astrocytes and catecholamine terminals. The precise relationship between astrocytic $\beta \mathrm{AR}$ and $\mathrm{TH}$-immunoreactive axonal varicosities in intact visual cortex was revealed for the first time by the present dual electron microscopic immunocytochemical results. These results indicate that $\beta \mathrm{AR}$ does not occur solely within astrocytic processes facing catecholamine axon terminals. In fact, $\beta$ AR404 immunoreactivity predominated along portions of astrocytes that were separated from catecholamine terminals. This suggests that the neuropil space affected by catecholamines may not be confined to synaptic clefts or the immediate periphery of catecholamine varicosities.

Structural differences in synaptic specializations, such as vesicular number and pre- and postsynaptic densities, have been suggested to reflect differences in the efficacy of transmitter release (reviewed by Forscher et al., 1987; Greenough and Chang, 1988). Although these changes usually are thought to occur during development, large differences in the ultrastructure of catecholamine axons were also notable in the adult visual cortex (see also Séguéla et al., 1990). Moreover, the differences in catecholamine synapses were accompanied by differences in their association with $\beta$ AR404-immunoreactive astrocytes. Thus, catecholamine axon terminals that exhibited easily identifiable synaptic specializations with dendrites were in direct contact with $\beta$ AR404-immunoreactive astrocytic processes: other catecholamine axons contained fewer vesicles and lacked morphologically identifiable synaptic specializations. These growth conelike axon terminals were not juxtaposed to $\beta$ AR404-immunoreactive astrocytes. Since activation of astrocytic $\beta$ AR can lead to extension of the distal astrocytic processes (see $\beta \mathrm{AR}$ and astrocytic cytoskeleton above), the juxtaposition between well- 
developed catecholamine synapses and astrocytes may reflect chemotropism of the distal processes of astrocytes toward neuronal sources of catecholamines. Conversely, the maintenance of close juxtaposition between astrocytic processes and catecholamine axons may require the active release of catecholamines from the catecholamine terminal.

It is widely assumed that vesicular fusion with the plasma membrane of axons occurs mostly at presynaptic specializations, yet such $\omega$-profiles (Heuser and Reese, 1981) are rarely seen in the CNS. In the case of noradrenaline varicosities, the possibility remains that the vesicles may fuse with terminal membrane that is deprived or away from a junctional specialization and, instead, surrounded by astrocytes bearing $\beta \mathrm{AR}$.

$\beta A R 404$-immunoreactive astrocytes at noncatecholamine synaptic junctions. $\beta \mathrm{AR}$-immunoreactive astrocytic processes that coursed near catecholamine synaptic terminals were frequently juxtaposed also to asymmetric, unlabeled synaptic junctions. Based on their morphological characteristics, the majority of these unlabeled synapses were likely to be excitatory, utilizing L-glutamate as neurotransmitters (Somogyi et al., 1986; Morrison et al., 1989). Recent works led by Hansson (Hansson et al., 1985; Hansson and Ronnback, 1989; Hansson, 1990) have demonstrated that activation of astrocytic $\beta \mathrm{AR}$ decreases uptake of neuronally released $\mathrm{L}$-glutamate into astrocytic processes. Thus, the catecholamine dependence for long-term potentiation in the hippocampus (Neuman and Harley, 1983; Hopkins and Johnston, 1984; Stanton and Sarvey, 1985) and perhaps also in the neocortex may reflect the participation of astrocytic $\beta A R$. Specifically, activation of locus coeruleus during alertness (reviewed by Aston-Jones, 1985) may activate astrocytic $\beta \mathrm{AR}$ in the visual cortex, leading to elevations in synaptic levels of L-glutamate, the consequence of which may be long-term potentiation (Bekkers and Stevens, 1990; reviewed by Bashir et al., 1991) or excitotoxicity (reviewed by Choi and Rothman, 1990). This working hypothesis must be tested in future studies that examine the ultrastructural relationships among catecholamine and glutamate receptors.

\section{References}

Aoki C, Pickel VM (1990) Ultrastructural immunocytochemical evidence for presynaptic localization of $\beta$-adrenergic receptors in the striatum and cerebral cortex of rat brain. Ann NY Acad Sci 604:582585.

Aoki C, Pickel VM (1992a) C-Terminal tail of $\beta$-adrenergic receptors: immunocytochemical localization within astrocytes and their relation to catecholaminergic neurons in $\mathrm{n}$. tractus solitarii and area postrema. Brain Res, in press.

Aoki C, Pickel VM (1992b) Ultrastructural relations between $\beta$-adrenergic receptors and catecholaminergic neurons. Brain Res Bull, in press.

Aoki C, Kaufman D, Rainbow TC (1986) The ontogeny of the laminar distribution of $\beta$-adrenergic receptors in the visual cortex of cats, normally reared and dark-reared. Dev Brain Res 27:109-1 16.

Aoki C, Joh TH, Pickel VM (1987) Ultrastructural localization of $\beta$-adrenergic receptor-like immunoreactivity in the cortex and neostriatum of rat brain. Brain Res 437:264-282.

Aoki C, Zemcik BA, Strader CD, Pickel VM (1989) Cytoplasmic loop of $\beta$-adrenergic receptors: synaptic and intracellular localization and relation to catecholaminergic neurons in the nuclei of the solitary tracts. Brain Res 493:331-347.

Aston-Jones G (1985) Behavioral functions of locus coeruleus derived from cellular attributes. Physiol Psychol 13:118-126.

Barres BA, Chun LLY, Corey DPA (1990) Ion channels in vertebrate glia. Annu Rev Neurosci 13:441-474.

Bashir AI, Alford S, Davies SN, Randall AD, Collingridge GL (1991) Long-term potentiation of NMDA receptor-mediated synaptic transmission in the hippocampus. Nature 349:156-158.
Bear MF, Singer W (1986) Modulation of visual cortical plasticity by acetylcholine and noradrenaline. Nature 320:172-176.

Bekkers JM, Stevens CF (1990) Presynaptic mechanism for long-term potentiation in the hippocampus. Nature 346:724-730.

Bicknell RJ, Luckman SM, Inenaga K, Mason WT (1989) Beta-adrenergic and opioid receptors on pituicytes cultured from adult rat neurohypophysis: regulation of cell morphology. Brain Res Bull 22: 379-388.

Bouvier M, Hausdorff WP, DeBlasi A, O'Dowd BF, Kobilka BK, Caron MG, Lefkowitz RJ (1988) Removal of phosphorylation sites from the beta ${ }_{2}$-adrenergic receptor delays onset of agonist-promoted desensitization. Nature 333:370-373.

Bowman CL, Kimelberg HK (1984) Excitatory amino acids directly depolarize rat brain astrocytes in primary culture. Nature 311:656659.

Browning ET, Ruina M (1984) Glial fibrillary acidic protein: norepinephrine stimulated phosphorylation in intact $\mathrm{C}-6$ glioma cells. J Neurochem 42:718-726.

Burgess SK, McCarthy KD (1985) Autoradiographic quantitation of beta-adrenergic receptors on neural cells in primary cultures. I. Pharmacological studies of [ $\left.{ }^{125} \mathrm{I}\right]$ pindolol binding of individual astroglial cells. Brain Res 335:1-9.

Chan J, Aoki C, Pickel VM (1990) Optimization of differential immunogold-silver and peroxidase labeling with maintenance of ultrastructure in brain sections before plastic embedding. J Neurosci Methods 33:113-127.

Chesler M (1990) The regulation and modulation of $\mathrm{pH}$ in the nervous system. Prog Neurobiol 34:401-427.

Choi DW, Rothman SM (1990) The role of glutamate neurotoxicity in hypoxic-ischemic neuronal death. Annu Rev Neurosci 13:171182.

Cornell-Bell AH, Finkbeiner SM, Cooper MS, Smith SJ (1990) Glutamate induces calcium waves in cultured astrocytes: long-range glial signaling. Science 247:470-473.

Descarries L, Séguéla P, Watkins KC (1991) Nonjunctional relationships of monoamine axon terminals in the cerebral cortex of adult rat. In: Advances in neuroscience, Vol 1, Volume transmission in the brain: novel mechanism for neural transmission (Fuxe K, Agnati LF, eds), pp 53-62. New York: Raven.

Dixon RAF, Kobilka BK, Strader DJ, Benovic JL, Dohlman HG, Frielle T, Bolanowski MA, Bennett CD, Rands E, Diehl RE, Mumford RA, Slater EE, Sigal IS, Caron MG, Lefkowitz RJ, Strader CD (1986) Cloning of the gene and cDNA for mammalian beta-adrenergic receptor and homology with rhodopsin. Nature 321:75-79.

Emorine LJ, Marullo S, Briend-Sutren M-M, Patey G, Tate K, DelavierKlutchko C, Strosberg AD (1990) Molecular characterization of the human $\beta_{3}$-adrenergic receptor. Science 245:1118-1121.

Foote SL, Morrison JH (1987) Extrathalamic modulation of cortical function. Annu Rev Neurosci 10:67-95.

Forscher P, Kaczmarek LK, Buchanan JA, Smith SJ (1987) Cyclic AMP induces changes in distribution and transport of organelles within growth cones of Aplysia bag cell neurons. J Neurosci 7:3600-3611.

Fuxe K, Agnati LF, eds (1991) Advances in Neuroscience, Vol 1, Volume transmission in the brain: novel mechanisms for neural transmission. New York: Raven.

Gordon B, Mitchell B, Mohtadi K, Roth E, Tseng Y, Turk F (1990) Lesions of nonvisual inputs affect plasticity, norepinephrine content and acetylcholine content of visual cortex. J Neurophysiol 64:18511860.

Gray EG (1959) Axo-somatic and axo-dendritic synapses of the cerebral cortex. J Anat 93:420-433.

Greenough WT, Chang F-LF (1988) Plasticity of synapse structure and pattern in the cerebral cortex. In: Cerebral cortex, Vol 7, Development and maturation of cerebral cortex (Peters A, Jones EG, eds), pp 391-440. New York: Plenum.

Hansson E (1990) Receptor regulation of amino acid uptake in astroglial cells. Paper presented at Society for neuroscience 1990 satellite symposium: glial cells as targets of central noradrenergic systems: evidence and functional significance.

Hansson E, Ronnback L (1989) Regulation of glutamate and GABA transport by adrenoceptors in primary astroglial cell cultures. Life Sci 44:27-34

Hansson E, Eriksson P, Nilsson M (1985) Amino acid and monoamine transport in primary astroglial cultures from defined brain rcgions. Neurochem Res 10:1335-1341. 
Hayat MA (1981) Fixation for electron microscopy. New York: Academic.

Hertzberg EL, Lawrence TS, Gilula NB (1981) Gap junctional communication. Annu Rev Physiol 43:479-491.

Heuser JE, Reese TS (1981) Structural changes after transmitter release at the frog neuromuscular junction. J Cell Biol 88:564-580.

Hirata H, Slater NT, Kimelberg HK (1983) $\alpha$-Adrenergic receptormediated depolarization of rat neocortical astrocytes in primary culture. Brain Res 270:358-362.

Hopkins WF, Johnston D (1984) Frequency-dependent noradrenergic modulation of long-term potentiation in the hippocampus. Science 226:350-351.

Hsu S, Raine L, Fanger H (1981) Use of avidin-biotin-pcroxidase complex $(\mathrm{ABC})$ in immunoperoxidase techniques: a comparison between $\mathrm{ABC}$ and unlabeled antibody (PAP) procedures. J Histochem Cytochem 29:577-580.

Itakura T, Kasamatsu T, Pettigrew JD (1981) Norepinephrine-containing terminals in kitten visual cortex: laminar distribution and ultrastructure. Neuroscience 6:159-175.

Jones LS, Gauger LL, Davis JN (1985) Anatomy of brain alpha ${ }_{1-}$ adrenergic receptors: in vitro autoradiography with [ $\left.{ }^{125} \mathrm{I}\right]$-Heat. J Comp Neurol 231:190-208.

Jonsson G, Kasamatsu T (1983) Maturation of monoamine neurotransmitters and receptors in cat occipital cortex during postnatal critical period. Exp Brain Res 50:449-458.

Kalnins VI, Subrahmanyan L, Opas M (1986) The cytoskeleton. In: Astrocytes, Vol 3, Cell biology and pathology of astrocytcs (Fedoroff S, Vernadakis A, eds), pp 27-60. New York: Academic.

Kasamatsu T (1987) Norepinephrine hypothesis for visual cortical plasticity: thesis, antithesis and recent development. Curr Top Dev Biol 21:367-389.

Kimelberg HK (1986) Catecholamine and serotonin uptake in astrocytes. In: Astrocytes, Vol 2, Biochemistry, physiology and pharmacology of astrocytes (FedoroffS, Vernadakis A, eds), pp 107-131. New York: Academic.

King JC, Lechan RM, Kuigel G, Anthony ELP (1983) Acrolein: a fixative for immunocytochemical localization of peptides in the central nervous system. J Histochem Cytochem 31:62-68.

Lohse MJ, Benovic JL, Codina JF, Caron MG, Lefkowitz RJ (1990) Beta-arrestin: a protein that regulates beta-adrenergic receptor function. Science 248:1547.

MacVicar BA, Tse FWY, Crichton SA, Kettenmann H (1989) GABAactivated $\mathrm{Cl}^{-}$channels in astrocytes of hippocampal slices. J Neurosci 9:3577-3583.

Madison DV, Nicoll RA (1982) Noradrenaline blocks accommodation of pyramidal cell discharge in the hippocampus. Nature 299:636-638.

Masurovsky ER, Bunge RP (1968) Fluoroplastic coverslips for longterm nerve tissue culture. Stain Technol 43:161-165.

Morrison SF, Callaway J, Milner TA, Reis DJ (1989) Glutamate in the spinal sympathetic intermediolateral nucleus: localization by light and electron microscopy. Brain Res 503:5-15.

Mugnaini E (1986) Cell junctions of astrocytes, ependyma and related cells in the mammalian central nervous system, with emphasis on the hypothesis of a generalized functional syncytium of supporting cells. In: Astrocytes, Vol 1, Development, morphology, and regional specialization of astrocytes (Fedoroff S, Vernadakis A, eds), pp 329371. New York: Academic.

Narumi S, Kimelberg HK, Bourke RL (1978) Effects of norepinephrine on the morphology and some enzyme activities of primary monolayer cultures from rat brain. J Neurochem 31:1479-1480.
Neuman RS, Harley CW (1983) Long-lasting potentiation of the dentate gyrus population spike by norepinephrine. Brain Res 273:162165.

Pearson WR, Lipman EDJ (1988) Improved tools for biological sequence comparison. Proc Natl Acad Sci USA 85:2444-2448.

Peters A, Palay SL, Webster HD (1991) The fine structure of the nervous system, 3d ed. New York: Oxford UP.

Rainbow TC, Parsons B, Wolff BB (1984) Quantitative autoradiography of $\beta_{1}$ and $\beta_{2}$ adrenergic receptors in rat brain. Proc Natl Acad Sci USA 81:1585-1589.

Rougon G, Noble M, Mudge AW (1983) Neuropeptides modulate the beta-adrenergic response of purified astrocytes in vitro. Nature 305: 715.

Saper CB (1984) Diffuse cortical projection systems: anatomical organization and role in cortical function. In: Handbook of physiologythe nervous system V, pp 169-210. Bethesda, MD: American Physiological Society.

Séguéla P, Watkins KC, Geffard M, Descarries L (1990) Noradrenaline axon terminals in adult rat neocortex: an immunocytochemical analysis in serial thin sections. Neuroscience 35:249-264.

Shain WG, Forman DS, Madelian V, Turner JN (1987) Morphology of astroglial cells is controlled by beta-adrenergic receptors. J Cell Biol 105:2307-2314.

Sibley DR, Lefkowitz RJ (1985) Molecular mechanisms of receptor desensitization using the $\beta$-adrenergic receptor-coupled adenylate cyclase system as a model. Nature 317:124-129.

Somogyi P, Halasy K, Somogyi J, Storm-Mathisen J, Ottersen OP (1986) Quantification of immunogold labelling reveals enrichment of glutamate in mossy and parallel fibre terminals in cat cerebellum. Neuroscience 19:1045-1050.

Spray DC, de Carvalho AC, Moreno AP, Bennett MVL, Hertzberg L (1990) Regulation of gap junctions: new insights from molecular approaches. In: Society for neuroscience short course syllabus: modulation of neuronal activity and connectivity (Levitan IB, ed), pp 28 29. Bethesda, MD: Society for Neuroscience.

Stanton PK, Sarvey JW (1985) Depletion of norepinephrine, but not serotonin, reduces long-term potentiation in the dentate gyrus of rat hippocampal slices. J Neurosci 5:2169-2176.

Stone EA, Ariano MA (1989) Are glial cells targets of the central noradrenergic system? A review of the evidence. Brain Res Rev 14: 297-309.

Stone EA, Sessler FM, Weimin L (1990) Glial localization of adenylate-cyclase-coupled beta-adrenoceptors in rat forebrain slices. Brain Res 530:295-300.

Strader CD, Sigal IS, Register RB, Candelore MR, Rands E, Dixon RAF (1987a) Identification of residues required for ligand binding to the $\beta$-adrenergic receptor. Proc Natl Acad Sci USA 84:4384-4388.

Strader CD, Sigal IS, Blake AD, Cheung AH, Register BS, Rands E, Zemcik BA, Candelore MR, Dixon RAF (1987b) The carboxyl terminus of the hamster $\beta$-adrenergic receptor expressed in mouse $L$ cells is not required for receptor sequestration. Cell 49:855-863.

Usowicz MM, Gallo V, Cull-Candy SG (1989) Multiple conductance channels in type- 2 cerebellar astrocytes activated by excitatory amino acids. Nature 339:380-383.

Watabe K, Nakai K, Kasamatsu T (1982) Visual afferents to norepinephrine-containing neurons in cat locus coeruleus. Exp Brain Res 48:66-80.

Zagon IA, Higbee R, Riederer BM, Goodman SR (1986) Spectrin subtypes in mammalian brain: an immunoelectron microscopic study. J Neurosci 6:2977-2986. 